Bradish, C. J., Brooksby, J. B. \& Dillon, Jun., J. F. (1956). J. gen. Microbiol. 14, 290-314

\title{
Biophysical Studies of the Virus System of Vesicular Stomatitis
}

\author{
By C. J. BRADISH, J. B. BROOKSBY AND J. F. DILLON, Jun.* \\ The Research Institute (Animal Virus Diseases), Pirbright, Surrey
}

\begin{abstract}
SUMMARY : Biophysical studies of the virus system of vesicular stomatitis passaged in eggs showed that the major part of the infectivity was associated with a component of sedimentation coefficient $625 \mathrm{~S}$. A component of sedimentation coefficient $330 \mathrm{~S}$ was observed also, and is probably a non-infective product of the disintegration of the $625 \mathrm{~S}$ component. These components contribute about $35 \%$ of the total complement-fixing activity of the virus system. All infective materials were handled in subdued light (Skinner \& Bradish, 1954). Electron micrographs of concentrates of the infective fraction revealed rods, of length $175 \mathrm{~m} \mu$. and diameter $69 \mathrm{~m} \mu$., and almost spherical granules of diameter $65 \mathrm{~m} \mu$. These particles are identified with the $625 S$ and $330 S$ sedimentation components. The remaining $65 \%$ of the total complement-fixing activity was associated with two discrete components of sedimentation coefficients about $20 S$ and $6 S$. The first of these components may contribute up to $0 \cdot 1 \%$ of the total infectivity of the virus system. The structure of the virus system is discussed in relation to the data obtained.
\end{abstract}

Ultracentrifugal studies of the virus system of foot-and-mouth disease (Bradish, Brooksby, Dillon \& Norambuena, 1952) demonstrated that infectivity and complement-fixing activity were associated with discrete components of sedimentation coefficients $70 \mathrm{~S}$ and $8 \mathrm{~S}$, respectively. These values correspond with equivalent particle diameters of about 20 and $7 \mathrm{~m} \mu$., respectively. The extension of studies of this type to the virus system of vesicular stomatitis presents advantages because of the greater mass of the infective particle which, on the basis of earlier ultrafiltration and ultracentrifugation data (Galloway \& Elford, 1933; Elford \& Galloway, 1937) has an equivalent diameter of about $75 \mathrm{~m} \mu$. This larger particle facilitates the use of certain biophysical methods which were not employed in the previous study (Bradish et al. 1952). Of particular value is the comparison which may be made between the data obtained by the biological assay of ultracentrifugal fractions and those derived by direct optical-analytical ultracentrifugation and by electron microscopy. The results obtained are presented in this paper.

\section{METHODS}

\section{Handling in subdued light}

It was observed by Skinner \& Bradish (1954) that the infectivity of suspensions of many viruses, including those of the virus of vesicular stomatitis, was decreased significantly by exposure to light. Special precautions were taken

* Visiting worker from Bureau of Animal Industry, Agricultural Research Administration, U.S. Department of Agriculture, Washington, D.C. Present address : Bell Telephone Laboratories, Murray Hill, N.J. 
therefore to minimize the possibility of errors arising from this cause. When infectivity was to be studied the successive operations, from the collection of the infective starting material to the inoculation of the dilutions of experimental fractions, were conducted in subdued light. A satisfactory lighting for this purpose was provided by one or two $15 \mathrm{~W}$. red lamps placed at least $20 \mathrm{in}$. from the virus suspensions. This represents a maximum degree of illumination of about $0 \cdot 3$ foot-candle and compares with a degree of illumination of 200 to $1200 \mathrm{ft} . c$. at a typical laboratory bench.

\section{The virus strains used and the preparation of virus suspensions}

Vesicular stomatitis virus. Virus of both immunological types was used: strain Ind.C. of the Indiana type and strain NJ.M of the New Jersey type. These strains were maintained in developing eggs by passage by the chorioallantoic method (Beveridge \& Burnet, 1946) at approximately weekly intervals. Before inoculation the eggs were incubated at $36^{\circ}$ in a commercial forced-draught incubator. For the production of infective fluid, inocula of $10^{4}$ ID 50 doses, containing 200 to 300 units penicillin, were dropped on to the chorioallantoic membranes. The embryos died within 18-24 hr. With virus of strain NJ.M eggs of 7-days incubation were used since in older eggs this strain did not always kill the embryos. For virus of strain Ind.C only 9- or 10-day eggs were used because of the greater yield of infective fluid. Inoculated eggs were incubated at $35^{\circ}$ in an ordinary bacteriological incubator, and as soon as possible after the deaths of the embryos the allantoic and amniotic fluids were withdrawn. Fluids from each batch of eggs were pooled and stored at $4^{\circ}$ for not more than $24 \mathrm{hr}$. before ultracentrifugal and other studies. Unless stated otherwise in the text, all data refer to experiments with pooled egg fluids infected with virus of strain Ind.C.

Estimation of infectivity of virus suspensions. Serial tenfold dilutions of the virus suspensions were prepared in a medium consisting of $0 \cdot 15 \mathrm{M}-\mathrm{NaCl}$ adjusted to $\mathrm{pH} 7 \cdot 6$ by the addition of phosphate salts to a total molarity of 0.005. This medium was used as the standard diluent throughout this study. Unless stated otherwise, 10 or 12 eggs were inoculated with each dilution of the series and were subsequently examined twice daily for 3 days. In titrations of the infectivity of suspensions of virus of strain NJ.M eggs of 7-days incubation were used; with suspensions of virus of strain Ind.C eggs of 7 or 8 days, or more rarely 9 or 10 days were used. The specificity of death of each embryo was determined by a complement-fixation test on a small sample of pooled allantoic and amniotic fluids from each egg. Samples from eggs classified as 'specifically dead' fixed 2 M.H.D. of complement in the presence of excess of the homologous guinea-pig antiserum.

Calculation and presentation of infectivity data. The $50 \%$ end-point dilutions were calculated by the method of Reed \& Muench (1938) and only eggs classified as 'alive' or 'specifically dead' were included. For convenience of presentation infectivity titres are expressed as the logarithms to the base 10 of the reciprocals of the $50 \%$ end-point dilutions. Thus a $50 \%$ end-point dilution of 
$10^{-6 \cdot 0}$ is expressed as an infectivity titre of 6.0. An infectivity titre of $<6 \cdot 0$ indicates an end-point dilution between $10^{\circ}$ and $10^{-6 \cdot 0}$.

Estimation of complement-fixing activity. Complement-fixing activity was estimated by the method described by Brooksby (1952). Serial twofold dilutions of the experimental sample were tested with excess of the specific antisera. In view of the observed greater lability of the antigenic material in vesicular stomatitis the accuracy of determination of complement-fixing activity in this work is about $\pm 15 \%$ and is inferior to that observed in previous studies of the virus system of foot-and-mouth disease (Bradish et al. 1952).

\section{Ultracentrifugation}

Ultracentrifugation in angle rotors. The methods employed were generally as described by Bradish et al. (1952). The Model E and Model L Spinco Ultracentrifuges (manufactured by the Specialised Instrument Corporation, Belmont, California, U.S.A.) were used with a range of angle rotors designed to accommodate capped Lusteroid tubes of capacity from $8 \mathrm{ml}$. (Rotor $C$, 14 Tubes) to $100 \mathrm{ml}$. (Rotor $L 20,10$ tubes). Before fractionation all materials were clarified by centrifugation so that, ideally, about $10 \%$ of the heaviest specific component to be separated was deposited with the non-specific gross material. In most cases only the upper nine-tenths of the supernatant fluids were retained for use. This ensured that the clarified starting materials were as free as possible from the gross materials which otherwise would have appeared in subsequent deposits. This clarification procedure, appropriately adjusted to the sedimentation properties of different fractions, was employed throughout this study.

During ultracentrifugation in the refrigerated vacuum chambers the loaded rotors were maintained at about $5^{\circ}$. After ultracentrifugation the tubes were withdrawn carefully from the cold rotor in groups of three or four and placed in a rack indicating the levels required for sampling. Supernatants were withdrawn without delay by means of capillary pipettes and teats. The tip of each capillary pipette was bent to the form of a $J$ and was held just below the meniscus in the tube as the supernatant was withdrawn slowly. After collection samples were stored at $4^{\circ}$ until required.

In experiments where it was desired to recover the deposits from the centrifuge tubes the supernatant fluids were withdrawn completely by means of straight capillary pipettes. The tubes were allowed to drain for a few minutes and any residual supernatant removed as before. The compact deposit remaining near the base of each tube was resuspended in a third of the required volume of the standard diluent by agitation for about half a minute in the bore of a capillary pipette. The remaining diluent was used to rinse the emptied tubes at least twice. Resuspensions and tube washings were then pooled, shaken well by hand, and returned to storage at $4^{\circ}$. In some experiments the deposit resuspensions were agitated mechanically during storage overnight. Resuspensions were clarified the following morning. Only the upper ninetenths of each clarification supernatant fluid was removed in order not to redisperse the lightly packed deposits. 
In most experiments deposits were resuspended in volumes of diluent equal to one-tenth to one-twentieth of the volume initially loaded into the centrifuge tubes. Thus the concentration per cycle was about 10 -fold or $\mathbf{2 0}$-fold and two cycles of sedimentation and clarification were required to obtain a concentration of about 400 -fold. In experiments on the concentration of the infective components the initial volumes of the clarified starting materials of $250 \mathrm{ml}$. to $1000 \mathrm{ml}$. were reduced to $2 \mathrm{ml}$. or less by two or three cycles of sedimentation and clarification extending over 2 or 3 days. Thus from 3 to 5 days elapsed between the collection of the infective pooled egg fluids and the titration and analysis of the derived fractions. It was generally unnecessary to exceed a concentration factor of about 400 since a final volume of about $1 \mathrm{ml}$. of each concentrated suspension was required for subsequent studies.

Procedures with a swinging-cup rotor. In addition to the angle rotors described above a special swinging-cup rotor was employed (Bradish et al. 1952 ) in conjunction with a range of fittings designed to allow samples of from 2.5 to $0.05 \mathrm{ml}$. to be centrifuged in strictly radial tubes. The four duralumin cups of the swinging-cup rotor were of $12.7 \mathrm{~mm}$. internal diameter and were used without inserts to receive $\mathbf{2 . 5} \mathrm{ml}$. each of the experimental samples. An anti-convection grid of $7 \mathrm{~mm}$. depth consisting of seven stainless steel tubes of $\mathbf{3 . 6} \mathrm{mm}$. internal diameter packed hexagonally within a larger stainless steel tube of $12.7 \mathrm{~mm}$. external diameter (obtained through the courtesy of Accles and Pollock, Ltd., Oldbury, Birmingham) was placed with fine forceps at the base of each loaded cup. Since the wall thickness of the steel tubes is only $0.23 \mathrm{~mm}$., the grids do not modify significantly the desired radial sedimentation of suspended particles yet provide protection against the convections which may arise during manipulation. At the conclusion of ultracentrifugation the samples of supernatant fluid were withdrawn carefully with J-capillary pipettes down to the level of the upper surface of the grids.

When volumes of less than $2.5 \mathrm{ml}$. were to be centrifuged plastic inserts of Perspex or Fluon (polymethyl methacrylate and polytetrafluoroethylene, products of Imperial Chemical Industries, Ltd.) were used. These inserts are cylinders of $12.7 \mathrm{~mm}$. external diameter, drilled and polished to form cylindrical cups of $3 \mathrm{~mm}$. or $6.5 \mathrm{~mm}$. internal diameter and $22 \mathrm{~mm}$. depth. To facilitate the collection of supernatant fluids and deposits the ends of the cups were rounded and the external surfaces of the cylinders ringed at the standard meniscus level and at the standard supernatant sampling depth. On the external surface of each cylinder were two longitudinal grooves which permitted handling with forceps and allowed each insert to be held securely between vertical pins on the sampling stand. Thus a reproducible procedure was available for the ultracentrifugation of volumes as low as $0.05 \mathrm{ml}$. The sampling procedures employed were as described for the tubes of the angle rotors.

Control tests indicated that neither infectivity nor complement-fixing activity was influenced significantly by the storage of samples in plastic or duralumin cups for $24 \mathrm{hr}$. at $4^{\circ}$.

Calculation and presentation of ultracentrifugal data. It was shown in the previous paper (Bradish et al. 1952) that the process of centrifugation in radial 
or inclined tubes may be represented to a first approximation by an equation of the form

$$
S G=\left(K \log _{10} \frac{r}{r_{0}}\right)\left(1-\frac{C}{C_{0}}\right)
$$

where $r_{0}$ is the radius of rotation of the meniscus in the centrifuge tube, $r$ the radius of rotation at the sampling depth and $C_{0}$ the initial concentration of the component of sedimentation coefficient $S$ Svedberg units. $C$ is the concentration of this component in the standard supernatant sample defined by $r_{0}$ and $r$ following the centrifugation process $G$. The parameter $G$, defined in the previous paper, represents the integration of the square of the spin of the rotor over the period of centrifugation, including periods of acceleration and retardation. $G$ values have been calculated directly from the duration of the centrifugation process, and the total number of rotor turns. For convenience $G$ is expressed in terms of time in hours and spin in units of $10,000 \mathrm{rev} . / \mathrm{min}$. Thus centrifugation at a constant spin of $40,000 \mathrm{rev} . / \mathrm{min}$. for $2 \mathrm{hr}$. contributes 32 units to the overall value of $G$. These mixed practical units may be converted to reciprocal seconds by multiplication by the factor $4 \pi^{2} \times 10^{8}$.

The numerical constant $K$ has the value 5833 when sedimentation occurs in radial tubes and $5833 / 2 \cdot 6$, or 2240 , when sedimentation occurs in inclined tubes. The validity of this treatment of sedimentation in inclined tubes was discussed by Bradish et al. (1952). For any standardized sampling procedure the term $k=K \log _{10} r / r_{0}$ represents a constant which, once calculated from the dimensions of a rotor and its tubes, may be substituted in the equation $S G=k\left(1-\left(C / C_{0}\right)\right)$ and used to predict appropriate conditions for clarification and sedimentation or to estimate activity-average sedimentation constants from sampling and assay data. Characteristic values of the dimensionless constant $k$ are given in Table 1 for the rotors and tubes employed. Thus, when a component of sedi-

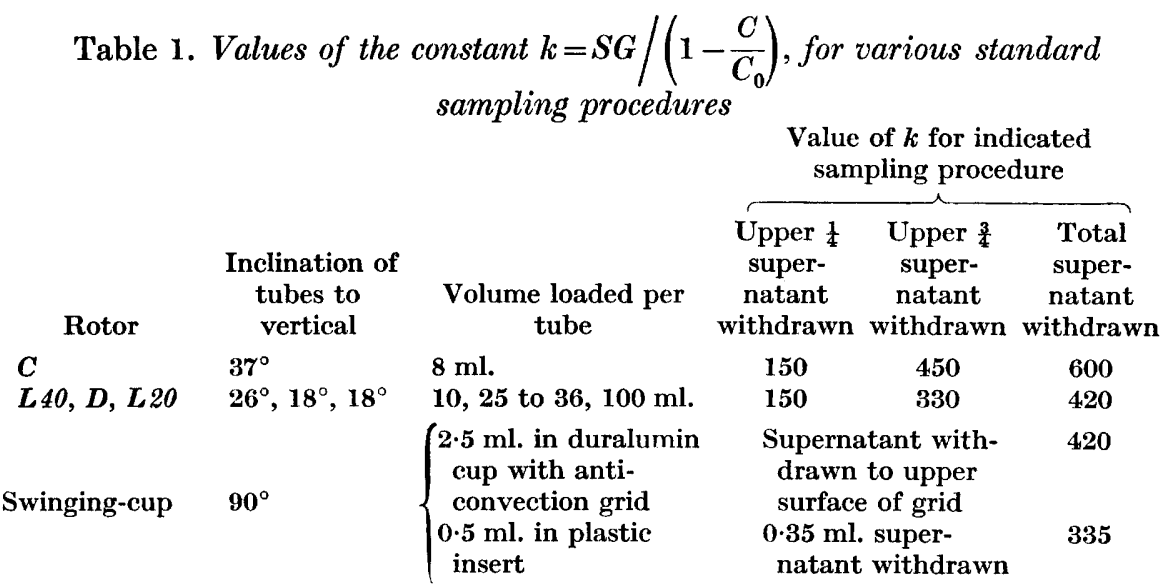

mentation coefficient $100 S$ is to be removed by centrifugation from the upper $6 \mathrm{ml}$. supernatant fluid in a $C$ rotor tube, a $G$ value of 4.5 units is required. This $G$ value would be obtained by bringing the $C$ rotor up to $20,000 \mathrm{rev} . / \mathrm{min}$., 
maintaining this spin for $1 \mathrm{hr}$., and then retarding the rotor at the standard rate. Alternatively, the same $G$ value would be obtained if the $C$ rotor were accelerated to $39,000 \mathrm{rev} . / \mathrm{min}$. and immediately retarded at the standard rate without any period at constant spin. This second condition enables the required $G$ value to be attained in the shortest time.

Optical-analytical ultracentrifugation. The Spinco A and B analytical rotors were employed. The sample to be studied was loaded into the sector cell of appropriate length and centrifuged in the vacuum chamber without cooling by refrigeration. The rotor speed was chosen to allow at least five successive sedimentation diagrams to be photographed during centrifugation at constant speed for not less than $1 \mathrm{hr}$. The positions of sedimentation boundaries were measured from the plates by means of a travelling microscope and the radius of rotation $(r)$ for each boundary was calculated from these in the usual manner. Sedimentation coefficients were calculated by the method of least squares from the paired values of $\log _{10} r$ and $G$. The optical-analytical sedimentation coefficients thus obtained are expressed in terms of water at $20^{\circ}$ according to the theory and data presented by Svedberg \& Pedersen (1940). A partial specific volume of 0.750 was assumed for all corrections, unless stated otherwise in the text. Sedimentation coefficients are expressed in Svedberg units $\left(10^{-13}\right.$ sec.) and designated by $S$.

Electron microscopy. Small drops of the concentrate to be studied were placed on formvar- or collodion-coated mounting grids. The concentrates were fixed either by the addition of one drop of $0 \cdot 1 \%$ osmium tetroxide solution to each drop of concentrate or by the exposure of the grid and drop to osmic vapour in a small sealed chamber. In both cases exposure continued for $30 \mathrm{~min}$. before the drops were allowed to evaporate to dryness. Buffer salts were removed from the specimen films by the application and removal of small drops of distilled water. The dried specimen films were shadowed at an angle of $\tan ^{-1}\left(\frac{1}{6}\right)$ or $\tan ^{-1}\left(\frac{1}{4}\right)$ by a layer of about $8 \mathrm{~A}$. of gold-manganin or $20 \mathrm{~A}$. of chromium before examination in an R.C.A. EMU $2 \mathrm{~b}$ electron microscope. This instrument was fitted with a compensated objective pole piece (Hillier \& Ramberg, 1947). Electron optical magnification was determined by the use of Dow polystyrene latex of empirical mean diameter 2590 A. (Backus \& Williams, 1948; Scott, 1949). Samples of latex were kindly supplied by Dr V. E. Cosslett and by Dr R. C. Backus.

Electron micrographs were taken at magnifications from $\times 8,000$ to $\times 16,000$. The dimensions of images of characteristic particles were measured directly from the plates with a travelling microscope providing an optical magnification of $\times 10$. Subjective errors were reduced by the measurement of the dimensions of every discrete particle which appeared on the plates.

Estimation of nitrogen concentration. The nitrogen contents of the fractions studied were determined by the micro-Kjeldahl procedure of Ma \& Zuazaga (1942), with the apparatus described by Markham (1942). Alternatively, colorimetric estimations based upon the Nessler procedure were employed. 


\section{RESULTS}

\section{Partition of the virus system}

As in the study of the virus system of foot-and-mouth disease (Bradish $e$ al . 1952) an attempt was made to distinguish, in the virus system of vesicular stomatitis, between the sedimentation properties of the components responsible for infectivity and complement-fixing activity. For this purpose samples of each of a number of clarified starting materials were subjected to centrifuga-

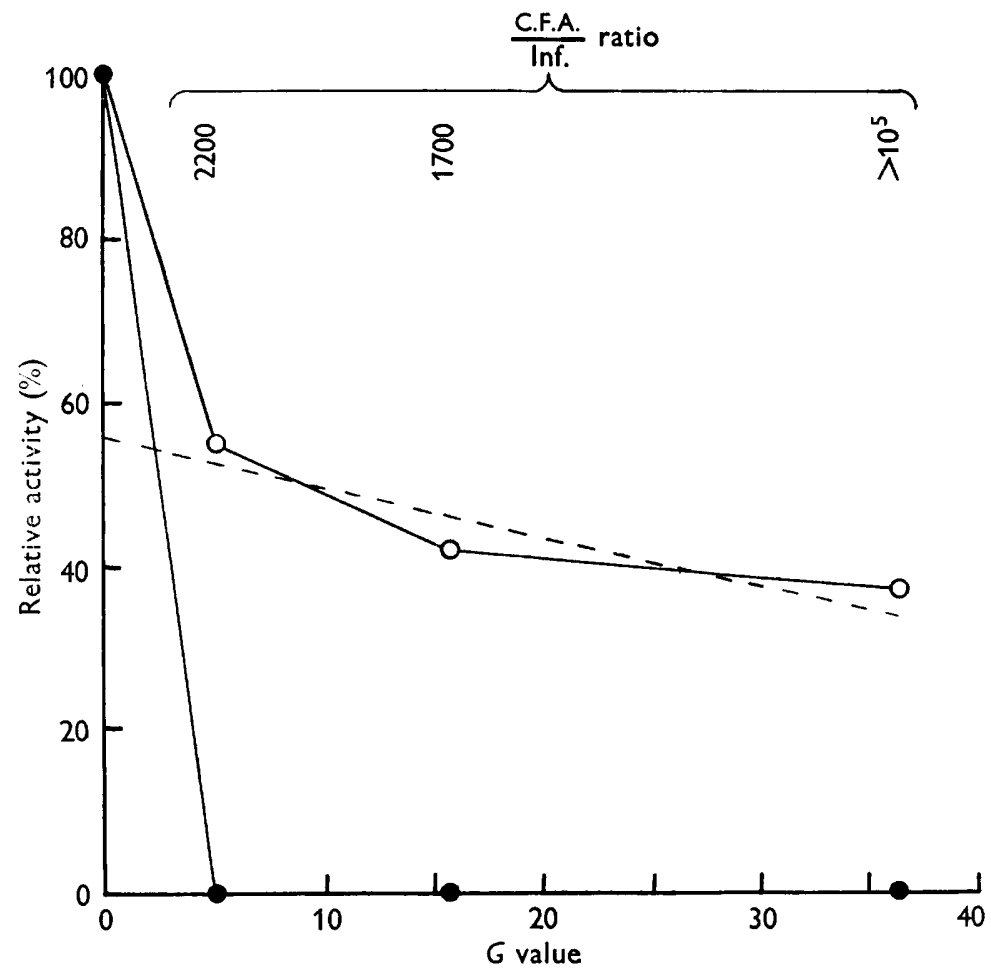

Fig. 1. Partition diagram showing decreases in activities of standard supernatant samples derived from a clarified starting material following ultracentrifugation in $0.5 \mathrm{ml}$. Perspex cups. $\mathrm{O}=$ complement-fixing activity; $O=$ infectivity.

tion at values of $G$ ranging from 1 to 40 units. At the conclusion of each period of sedimentation, standard volumes of supernatant fluid were withdrawn from the centrifuge tubes and assayed for infectivity and complement-fixing activity.

These experiments were made either with the $C$ rotor tubes, when standard $5 \mathrm{ml}$. volumes of supernatant fluids were withdrawn from the $8 \mathrm{ml}$. volumes loaded, or with the $6.5 \mathrm{~mm}$. plastic inserts of the swinging-cup rotor when standard $0.35 \mathrm{ml}$. volumes of supernatant fluids were withdrawn from $0.5 \mathrm{ml}$. volumes loaded. The results of four typical experiments are shown in Figs. 1 and 2. In each case the complement-fixing activity fell to between 40 and $60 \%$ 
of its initial value in the supernatant fluid obtained at the lowest value of $G$, and thereafter fell much less rapidly in supernatant fluids obtained at greater values of $G$.

Similar results were obtained in experiments in which the clarified starting materials were subjected to several cycles of centrifugation at a fixed value of $G$. The standard supernatant withdrawn from the tubes of one cycle served as the starting material for the following cycle. Fig. 3 illustrates the partition of activity observed in these experiments.
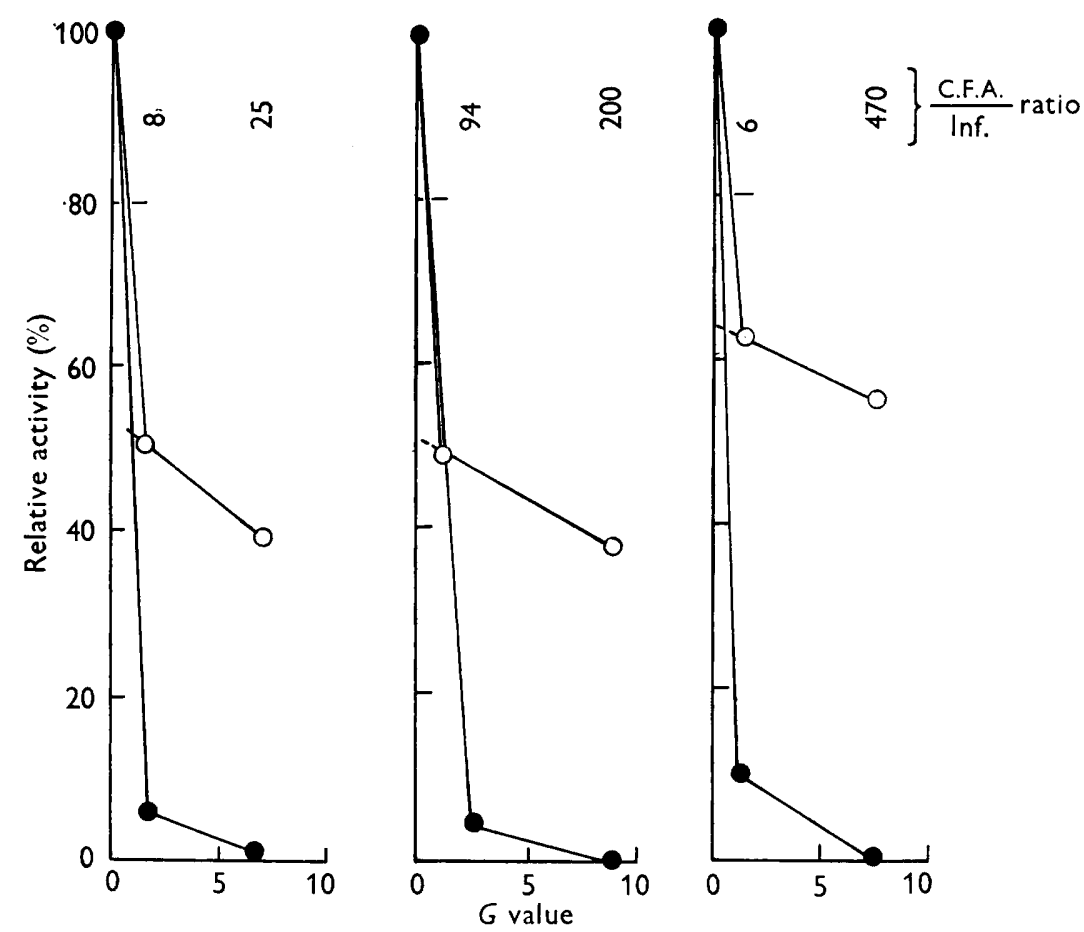

Fig. 2. Partition diagrams showing decreases in activities of standard supernatant samples derived from clarified starting materials following ultracentrifugation in $0.5 \mathrm{ml}$. Perspex cups. $O=$ complement-fixing activity; $O=$ infectivity.

In all of these experiments the infectivity titres of the standard supernatant samples obtained after centrifugation at 6 units of $G$ were about 3 logarithmic units lower than those of the clarified starting materials from which they were derived. It appeared likely that the discontinuity in the rate of fall of complement-fixing activity in supernatant samples arose from the presence of a rapidly sedimenting infective and complement-fixing component. The following experiments confirmed this view. Samples of supernatant fractions which retained about $50 \%$ of the initial complement-fixing activity and less than $1 \%$ of the initial infectivity were centrifuged at values of $G$ ranging from 1 to 40 units. Standard supernatant samples were then withdrawn and assayed. The data obtained are shown in Fig. 4 and indicate that the complement-fixing 


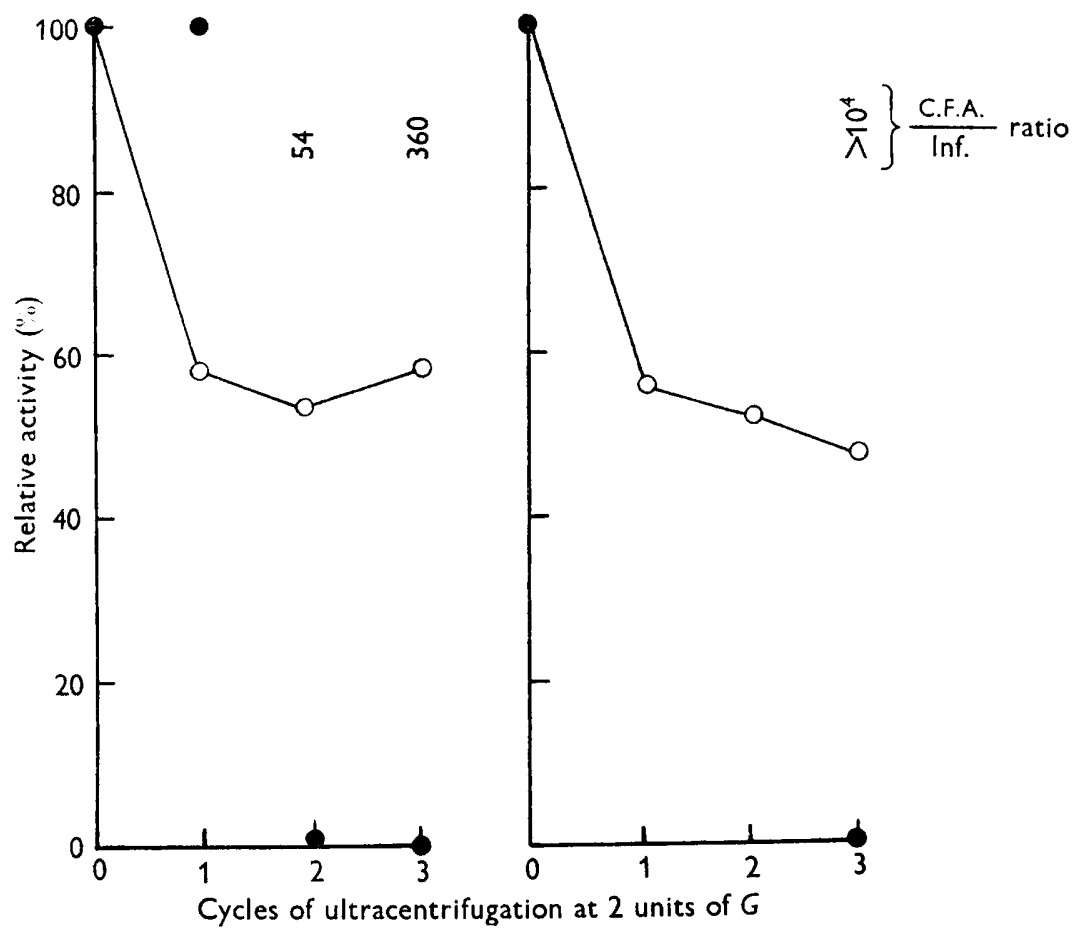

Fig. 3. Decreases in activities of standard supernatant samples derived from clarified starting materials following ultracentrifugation in inclined tubes of $C$ or $D$ rotors. $\mathrm{O}=$ complement-fixing activity; $\mathrm{O}=$ infectivity.

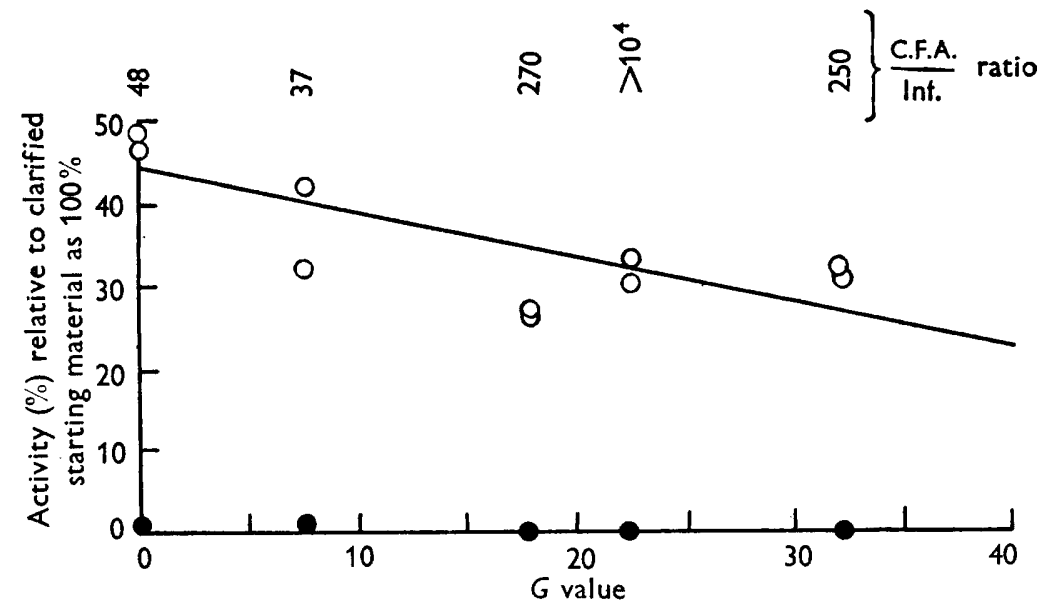

Fig. 4. Decrease in complement-fixing activity of standard supernatant samples derived from a complement-fixing fraction following ultracentrifugation in inclined tubes of $C$ rotor. $O=$ complement-fixing activity; $O=$ infectivity. 
activity of supernatant samples fell very slowly with $G$ and that the previous discontinuity at low values of $G$ was absent.

The distribution of complement-fixing activity and infectivity in any fraction may be stated conveniently in terms of the ratio of complement-fixing activity to infectivity, both expressed as percentages of their initial values for the clarified starting material: this ratio is by definition unity for each clarified starting material. The value of this ratio for the first and second supernatant samples in the experiment of Fig. 1, for example, was about 2000. This implies that these samples of the slower sedimenting fraction retained about $65 \%$ of the initial complement-fixing activity yet only 1 part in 3000 , or $0.03 \%$, of the initial infectivity. Thus increases in the ratio of complement-fixing activity to infectivity (C.F.A./Inf.) indicate the extent to which each cycle of ultracentrifugation removed the infective component from the complement-fixing fraction. The values of this ratio for the supernatant samples are given on the partition diagrams. That the removal of infectivity was not due to inactivation during manipulation is shown by the essentially quantitative recovery of infectivity in other parts of the same experiments. These data will be discussed later.

It was shown previously that data of the type shown in Figs. 1-3 provide the basis for the estimation of the percentage of the initial complement-fixing activity which is associated either with the larger infective component or with the smaller complement-fixing component. The appropriate extrapolation to the scale of activity is shown in these figures. In experiments of this type, extending over 2 years and with seventeen distinct samples of freshly collected pooled egg fluids, the percentage of the initial complement-fixing activity associated with the smaller complement-fixing fraction was within the range $55-80 \%$ in fifteen cases and close to $20 \%$ in the remaining two cases. Thus, in pooled egg fluids infected with Strain Ind.C of the virus of vesicular stomatitis, the rapidly sedimenting infective fraction is associated, in the majority of cases, with about $35 \%$ of the total complement-fixing activity.

\section{The complement-fixing component}

Sedimentation properties. Experiments made to determine the sedimentation coefficient of the complement-fixing component are summarized in Table 2. The fractions analysed were obtained as standard supernatants from $C$ rotor tubes following sedimentation of the infective components at 2 units of $G$. A complement-fixing component of sedimentation coefficient about $19 S$ was observed in these experiments. However, in otherwise similar experiments in which the supernatant fractions analysed were obtained by two or three cycles of ultracentrifugation at higher values of $G$, a complement-fixing component of sedimentation coefficient about $6 S$ was identified. A component of similarly low sedimentation coefficient was indicated by the analysis of data of the kind shown in Figs. 1 and 4. Thus, in the experiment of Fig. 1, the rate of fall of complement-fixing activity in standard supernatants was $0.61 \%$ per unit of $G$. Substitution of this value in the differential form of the equation 
$S G=k\left(1-\left(C / C_{0}\right)\right)$, putting $C_{0}=55 \%$ and $k=335$ appropriate to the sampling procedure, yields a sedimentation coefficient of $4 S$. Again, in the experiment of Fig. 4, the rate of fall of complement-fixing activity in standard supernatants was $0.64 \%$ per unit of $G$. Then, putting $C_{0}=45 \%$ and $k=380$, a sedimentation coefficient of $5 S$ is obtained.

Table 2. Sedimentation coefficient of complement-fixing component in first-cycle supernatant fractions. Determinations in $\mathbf{2 . 5} \mathrm{ml}$. unlined duralumin cups of swinging-cup rotor.

\begin{tabular}{|c|c|c|c|c|c|}
\hline \multirow[b]{2}{*}{ Starting material } & \multicolumn{4}{|c|}{ Radius of rotation (mm.) } & \multirow[b]{2}{*}{$\begin{array}{c}\text { Sedimentation } \\
\text { coefficient } \\
\text { (Svedberg units) }\end{array}$} \\
\hline & $\begin{array}{c}G \\
\text { value }\end{array}$ & Meniscus & $\begin{array}{c}\text { Sampling } \\
\text { level }\end{array}$ & $C / C_{0}$ & \\
\hline Allantoic fluid & $10 \cdot 3$ & $72 \cdot 0$ & $88 \cdot 5$ & $0 \cdot 69$ & $14 \cdot 5$ \\
\hline Allantoic fluid & $25 \cdot 0$ & $72 \cdot 0$ & $87 \cdot 0$ & $0 \cdot 33$ & $12 \cdot 4$ \\
\hline Allantoic mem- & $15 \cdot 0$ & $72 \cdot 0$ & $87 \cdot 0$ & $0 \cdot 29$ & $21 \cdot 5$ \\
\hline brane suspension & $15 \cdot 1$ & $72 \cdot 0$ & $87 \cdot 0$ & $0 \cdot 34$ & $20 \cdot 0$ \\
\hline Pooled egg fluids & $20 \cdot 4$ & $72 \cdot 0$ & $86 \cdot 5$ & $0 \cdot 44$ & $23 \cdot 0$ \\
\hline Pooled egg fluids & $22 \cdot 8$ & $72 \cdot 0$ & $86 \cdot 5$ & $0 \cdot 43$ & $20 \cdot 6$ \\
\hline Mean & - & 一 & 一 & - & $18 \cdot 7 \pm 4 \cdot 2$ \\
\hline
\end{tabular}

Equivalent values of the sampling constant $k$ are: 520 for sampling level at $88.5 \mathrm{~mm}$.; 480 for sampling level at $87.0 \mathrm{~mm}$.; 465 for sampling level at $86.5 \mathrm{~mm}$.

In view of this anomaly in the estimation of sedimentation coefficients experiments were made to test directly the possibility that the complementfixing component was polydisperse and that the observed sedimentation coefficients of about $20 S$ and $6 S$ were actually activity-averages appropriate to the distribution of two or more components defined by the conditions of the preliminary fractionation.

Polydispersity of the complement-fixing component. A typical test of the degree of polydispersity was made as follows. A standard supernatant fraction was prepared from a clarified pool of egg fluids by deposition of the infective components at 2.5 units of $G$ in the tubes of the $L 20$ rotor. This first-cycle supernatant fluid was ultracentrifuged again at 100 units of $G$ in the tubes of the $C$ rotor and three supernatant pools were obtained representing the top third (A), middle third (B) and bottom third (C) of the total supernatant in each tube. The deposits, of about $3 \mathrm{~mm}$. diameter, were resuspended in a third of the initial volume of standard diluent to provide, after clarification, a suspension (D) of the same volume as $\mathrm{A}, \mathrm{B}$ and $\mathrm{C}$. The sampling operations $\mathrm{A}, \mathrm{B}$, $\mathrm{C}$ and $\mathrm{D}$ were repeated following ultracentrifugation of the samples $\mathrm{A}, \mathrm{B}, \mathrm{C}$ and $\mathrm{D}$ at 100 units of $G$ as before. The sixteen samples obtained (AA, AB, .. down to DC, DD) were titrated for complement-fixing activity. The data obtained are shown in Table 3 and indicate a significant polydispersity of the complement-fixing fraction. A progressive decrease in the activity of the upper supernatant fluid was accompanied by an increase in the activity of the lower supernatant fluids and deposit resuspensions in the sample order: A, B, C, D. A single monodisperse component would have given rise to no differences between the distributions of activity in the second cycle groups 
since the samples loaded (A, B, C, D) would have differed only in degrees of activity and not in sedimentation properties. The overall recovery of complement-fixing activity from the supernatant samples was satisfactory $(80-110 \%)$ but that from the deposit group (DA, DB, DC, DD) was low, probably through loss during clarification of part of the activity of the deposit suspension (DD).

Table 3. A test of the polydispersity of the complement-fixing component

\begin{tabular}{|c|c|c|c|c|c|c|}
\hline \multirow{2}{*}{$\begin{array}{l}\text { Sample loaded } \\
\text { for second cycle } \\
\text { of ultracentri- } \\
\text { fugation }\end{array}$} & \multirow{2}{*}{$\begin{array}{c}\text { Complement-fixing } \\
\text { activity with } \\
\text { respect to starting } \\
\text { material } \\
(\%)\end{array}$} & \multicolumn{4}{|c|}{$\begin{array}{l}\text { Complement-fixing activity } \\
\text { of second cycle samples } \\
\text { with respect to sample } \\
\text { loaded } \\
(\%)\end{array}$} & \multirow{2}{*}{$\begin{array}{c}\text { Recovery of comple- } \\
\text { ment-fixing activity } \\
\text { with respect to } \\
\text { sample loaded } \\
(\%)\end{array}$} \\
\hline & & $\mathbf{A}$ & B & C & D & \\
\hline $\mathbf{A}$ & 54 & 100 & 50 & 89 & 0 & 80 \\
\hline B & 35 & 73 & 71 & 183 & 0 & 109 \\
\hline C & 89 & 32 & 57 & 172 & 20 & 94 \\
\hline D & 87 & 17 & 19 & 36 & 72 & 48 \\
\hline
\end{tabular}

A further confirmation of polydispersity was obtained by the sedimentation analysis of the extreme samples AA and DD. The samples were analysed in pairs in the duralumin cups of the swinging-cup rotor (cf. Table 2) fitted with anti-convection grids. Following ultracentrifugation at 19 units of $G$ the standard supernatants from the AA samples retained $86 \%$ of initial activity while those from the DD samples were inactive. These data imply sedimentation coefficients of about $4 S$ and at least $25 S$, respectively. A parallel experiment in which AA and $\mathrm{CC}$ samples were analysed indicated 57 and $27 \%$ retention of initial activity in the standard supernatant fluids, corresponding with sedimentation coefficients of $10 S$ and $17 S$, respectively. These typical data are consistent with the existence of two discrete complement-fixing components with sedimentation coefficients near $6 S$ and $20 S$, corresponding with equivalent particle diameters of 6 and $11 \mathrm{~m} \mu$., respectively.

Concentration and optical-sedimentation analysis of the complement-fixing components. Data presented in previous sections show that the complementfixing fraction is associated with a complex of at least two components with sedimentation coefficients between 5 and 30 Svedberg units. Attempts were then made to concentrate these components in order to obtain more exact optical-sedimentation data. The concentration procedure was similar to that described for the infective fraction apart from the greater $G$ values required for clarification and sedimentation. About $300 \mathrm{ml}$. of clarified starting material were clarified again in the tubes of the $D$ rotor at a $G$ value of 2 units. This deposited the infective fraction and yielded an upper supernatant pool consisting of the complement-fixing fraction. This fraction was centrifuged in the tubes of the $D$ rotor at a $G$ value of 45 units, sufficient to deposit components of sedimentation coefficient down to about $10 \mathrm{~S}$. Deposits of about $5 \mathrm{~mm}$. diameter were obtained and these were resuspended in $30 \mathrm{ml}$. of the standard diluent. The resuspension was clarified as before at 2 units of $G$ and then 
carried forward to a second and identical cycle of sedimentation and clarification. A faintly opalescent suspension of about $2 \mathrm{ml}$. volume was obtained which represented a 102-fold volume concentration and contained $0.06 \mathrm{mg} . \mathrm{N} / \mathrm{ml}$.

The complement-fixing activity of the concentrate, $1300 \%$ of that of the starting material, was associated with an infectivity titre of $5 \cdot 6$ (starting material, $6 \cdot 7$ ), corresponding with a complement-fixing activity/infectivity ratio of 160 . This value is less than that obtained for the unconcentrated complement-fixing fraction, but is much greater than the values of unity and about $0 \cdot 3$ for clarified starting materials and concentrates of the infective fraction. Thus the nature of the concentrate of the complement-fixing fraction is distinct from that of the infective fraction.

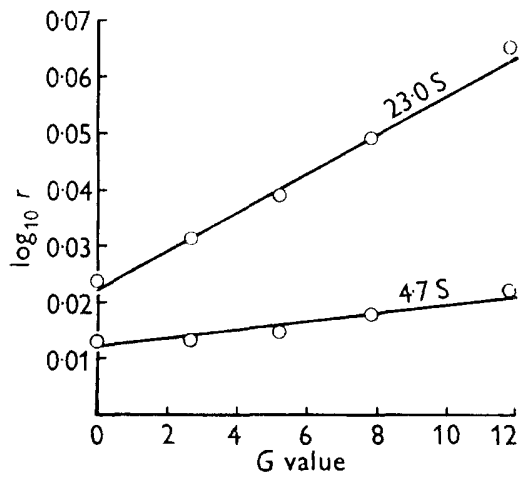

Fig 5

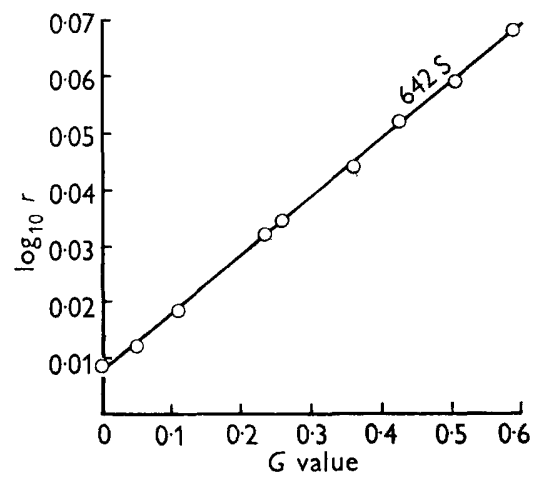

Fig. 6

Fig. 5. Sedimentation characteristics for components of concentrate of complement-fixing fraction. $r=$ radius of rotation of sedimentation boundary; $G=$ duration of centrifugation at constant speed expressed in standard integral form.

Fig. 6. Sedimentation characteristic for component of concentrate of infective fraction. $r=$ radius of rotation of sedimentation boundary; $G=$ duration of centrifugation at constant speed expressed in standard integral form.

The optical-sedimentation analysis of two separate concentrates of the complement-fixing fraction indicated components of sedimentation coefficients $21.5(20 \cdot 0$ and $23 \cdot 0)$ and about $6 \cdot 0(7 \cdot 3$ and $4 \cdot 7)$ Svedberg units, respectively. The sedimentation diagram and characteristics for one of these concentrates are shown in Pl. 1, fig. 1, and Fig. 5. These experiments confirm the existence in complement-fixing fractions of at least two distinct components.

\section{The major infective component}

Separation and concentration. Evidence presented later indicates that the major part of the infectivity of suspensions of the virus system of vesicular stomatitis is associated with a component of sedimentation coefficient $625 \mathrm{~S}$. Before concentration of this major infective component the starting materials were clarified at a $G$ value of 0.05 unit and the upper nine-tenths of the super- 
natant fluids retained for use. Clarified starting materials thus obtained were centrifuged at a $G$ value of 2 units which was sufficient to deposit a component of sedimentation coefficient $200-300 S$, according to the rotor selected. In this first sedimentation only very small deposits were obtained; slight, white, opalescent deposits of 1-2 mm. diameter being obtained in $C$ rotor tubes initially loaded with $8 \mathrm{ml}$. each of the clarified starting material. These deposits were dispersed readily in small volumes of the standard diluent and provided suspensions which remained turbid after clarification at a $G$ value of 0.05 unit. Further cycles of concentration by sedimentation and clarification under these conditions yielded larger deposits and clarified resuspensions of marked turbidity. These concentrated suspensions of the major infective component, when viewed in normal daylight, appeared blue by scattered light and reddish brown by transmitted light, a behaviour which suggested the presence of particles of asymmetrical form. Typical assay data for these concentrates are presented in Table 4.

Table 4. Concentration by ultracentrifugation of the major infective component in the virus system of vesicular stomatitis (strain Ind.C)

\begin{tabular}{|c|c|c|c|}
\hline Experiment number & 27 & 31 & 36 \\
\hline Volume of clarified starting material (ml.) & 500 & 250 & 1000 \\
\hline Infectivity titre of clarified starting material & $7 \cdot 2$ & $6 \cdot 8$ & $7 \cdot 5$ \\
\hline Number of cycles of sedimentation and clarification & 2 & 2 & 2 \\
\hline Concentration factor based on volume reduction & 300 & 250 & 400 \\
\hline Infectivity titre of concentrate & $9 \cdot 3$ & $8 \cdot 7$ & $9 \cdot 2$ \\
\hline Infectivity recovery in concentrate (\%) & 48 & 35 & 13 \\
\hline Complement-fixing activity of concentrate $(\%)$ & 3100 & 1900 & 2000 \\
\hline Complement-fixing activity recovery in concentrate $(\%)$ & 10 & 7 & $\mathbf{5}$ \\
\hline Ratio of complement-fixing activity to infectivity & $0 \cdot 2$ & $0 \cdot 2$ & $0 \cdot 4$ \\
\hline Nitrogen content of concentrate (mg. $\mathrm{N} / \mathrm{ml}$.) & $0 \cdot 35$ & - & $0 \cdot 22$ \\
\hline
\end{tabular}

The observed infectivity recoveries of from 10 to $50 \%$ suggest that a significant proportion of the infective component was lost during concentration. Probably the most severe loss occurred through the aggregation of the deposited material which was then either not resuspended or rejected during clarification. Also, even following efficient resuspension, aggregation of the infective component may influence the titration and result in a loss of infectivity. It may be noted that only about $10 \%$ of the complement-fixing activity of the clarified starting material was recovered in the infective concentrate. The ratio of complement-fixing activity to infectivity in these concentrates was about 0.3 and is not significantly different from the unit value attributed to the clarified starting material. These values contrast with those of 1000 or more observed for the fractions associated with the complement-fixing activity.

The nitrogen content of concentrates varied from 0.03 to $0.4 \mathrm{mg} . \mathrm{N} / \mathrm{ml}$. corresponding with concentration factors based on volume reduction of from 100 to 400 . These figures imply that the infectivity of the clarified starting materials was associated with a nitrogen content of about $0.0005 \mathrm{mg} . \mathrm{N} / \mathrm{ml}$., or only $0.1 \%$ of the total initial nitrogen content. 
Sedimentation data for the major infective component. A preliminary estimation of the sedimentation coefficient of the infective component in clarified starting materials was made by the capillary cell procedure described previously (Bradish et al. 1952). The data obtained are presented in Table 5 and indicate a mean minimum sedimentation coefficient of about 540 Svedberg units for the infective component. Further experiments of this kind were not made in view of the residue error already discussed (Bradish et al. 1952; Randrup, 1954), and in view of the difficulties of interpretation which arise as a result of the limited sensitivity of available titration procedures, particularly when more than one infective component may be present in the material to be analysed.

Table 5. Capillary sedimentation data for the infective component in clarified starting materials

$\begin{array}{ccccc} & \text { Initial infectivity } & & & \text { Sedimentation coefficient } \\ \text { Virus strain } & \text { titre } & G \text { value } & C / C_{0} & \text { (Svedberg units) } \\ \text { NJ.M } & 6 \cdot 5 & 0 \cdot 69 & 0 \cdot 04 & 446 \\ \text { Ind.C } & \mathbf{6 \cdot 8} & \mathbf{0 . 5 3} & \mathbf{0 \cdot 1 6} & \mathbf{5 0 5} \\ \text { Ind.C } & \mathbf{7 \cdot 6} & \mathbf{0 \cdot 4 9} & \mathbf{0 . 0 7} & \mathbf{6 0 7} \\ \text { *Ind.C } & \mathbf{7 \cdot 5} & \mathbf{0 \cdot 4 4} & \mathbf{0 . 1 3} & 630 \\ \text { Mean minimum sedimentation coefficient: } & & 540\end{array}$

* A suspension of guinea-pig pad epithelium. Fifteenth passage in guinea-pigs. Same material as employed in experiment of Fig. 8.

\section{Table 6. Optical-analytical sedimentation data for components} of the infective fraction

\begin{tabular}{|c|c|c|c|c|c|}
\hline \multirow[b]{2}{*}{$\begin{array}{c}\text { Experiment } \\
\text { number }\end{array}$} & \multicolumn{2}{|c|}{$\begin{array}{l}\text { Corrected sedimentation } \\
\text { coefficient (Svedberg units) }\end{array}$} & \multirow{2}{*}{$\begin{array}{c}\text { Approximate } \\
\text { nitrogen } \\
\text { concentration } \\
\text { of sample } \\
\text { (mg. } \mathrm{N} / \mathrm{ml} .)\end{array}$} & \multicolumn{2}{|c|}{$\begin{array}{l}\text { Weighted mean sedimentation } \\
\text { coefficient (Svedberg units) }\end{array}$} \\
\hline & $\begin{array}{c}\text { Primary } \\
\text { component }\end{array}$ & $\begin{array}{l}\text { Secondary } \\
\text { component }\end{array}$ & & $\begin{array}{l}\text { Primary } \\
\text { component }\end{array}$ & $\begin{array}{l}\text { Secondary } \\
\text { component }\end{array}$ \\
\hline 23 & 597 & $311)$ & & & \\
\hline 27 & 562 & 298 & $0 \cdot 30$ & 580 & 307 \\
\hline 36 & 582 & 316 & & & \\
\hline 21 & 615 & 321) & & & \\
\hline 34 & 681 & $333\}$ & $0 \cdot 10$ & 622 & 322 \\
\hline 35 & 599 & $317)$ & & & \\
\hline 16 & 670 & -1 & & & \\
\hline $16^{*}$ & 649 & 399 & 0.05 & 625 & - \\
\hline 18 & $\operatorname{sen} 642$ & - & & & \\
\hline 22 & 573 & -1 & & & \\
\hline
\end{tabular}

* Concentrate analysed again following resuspension of deposit and storage overnight at $1^{\circ}$.

In further experiments, concentrates of the major infective fraction of the kind described in the previous section and in Table 4 were analysed in the optical cells of the ultracentrifuge. Over a period of 3 years nine concentrates were analysed in this way and yielded the sedimentation data presented in Table 6. Plate 2, fig. 4 shows a typical sedimentation diagram, and Fig. 6 the linear relationship between the calculation parameters $\log _{10} r$ and $G$. 
In all concentrates a primary component, of sedimentation coefficient 560680 Svedberg units, was predominantly responsible for the turbidity and optical properties of the suspensions. In seven of the nine analyses there also appeared a secondary component of sedimentation coefficient 300-400 Svedberg units which contributed from 5 to $20 \%$ of the total sedimentable material.

The data obtained indicate a mean corrected sedimentation coefficient of 615 Svedberg units for the primary component and of 322 Svedberg units for the secondary component. Despite the extremely low concentration of specific material available for these analyses it is apparent from the data of Table 6 that much of the spread of the observed values arises from a dependence of sedimentation coefficient upon concentration. The extrapolation of these data to zero concentration indicates a sedimentation coefficient for each component which is about 10 Svedberg units higher than the mean value quoted above. Thus, for the purposes of further discussion, 625 and 330 Svedberg units will be adopted as the most probable sedimentation coefficients for the primary and secondary components in infinite dilutions of the infective fraction. The failure to observe any component of sedimentation coefficient greater than $625 S$ and the remarkably close agreement between this value and the minimum value of $540 S$ indicated by the capillary cell analyses of clarified starting materials (Table 5), justifies the conclusion that the component of sedimentation coefficient $625 S$ is the major infective component in the virus system of vesicular stomatitis and that the $330 S$ component is probably non-infective.

In one instance (Table 6) a concentrate of infective material was shown on first analysis to consist entirely of the primary $625 S$ component. The deposit obtained from this analysis was resuspended in the water-clear supernatant fluid without removal from the cell and the characteristically turbid suspension obtained was analysed again after storage at $+1^{\circ}$ overnight. The suspension now contained about $10 \%$ of the secondary $330 \mathrm{~S}$ component in addition to the primary component. This observation suggests, as discussed later, that the $330 S$ component is a degradation product of the predominant $625 S$ component.

All of the above analyses were made in the standard diluent, $0 \cdot 15 \mathrm{M}-\mathrm{NaCl}$ adjusted to $\mathrm{pH} 7 \cdot 6$ by the addition of $0 \cdot 005 \mathrm{M}$ phosphate salts. A preliminary analysis was made in a saline solution of greater density in order to obtain an estimate of the partial specific volume; data from this experiment are shown in Table 7. The calculated partial specific volume is close to $\mathbf{0 . 8 5 0}$ for both components and corresponds with a particle density of $1 \cdot 18$. These values must be regarded as provisional in view of the limited data and the uncertain influence of hydration. A partial specific volume of 0.850 was adopted for the correction of the sedimentation data presented in Table 6 . Correction in terms of the 'average protein' partial specific volume of $0 \cdot 750$ would lower all quoted sedimentation coefficients by $1 \cdot 72 \%$.

Estimation from sedimentation data of the particle dimensions of components of the infective fraction. The calculation of the dimensions of a particle requires, in addition to the sedimentation data, some knowledge of the shape of the 
particle. This additional information was provided in the present study by the electron microscopy of concentrates of the infective fraction; this demonstrated the existence in these materials of rods, of axial ratio 2.55 , and of almost spherical granules of axial ratio close to unity (see later). The inclusion of these

Table 7. Estimation of partial specific volumes of components of a concentrate of the major infective fraction

Medium

Sedimentation coefficient in medium at $20^{\circ}$

Primary component

Secondary component

Correction factors at $20^{\circ}$

$\rho / \rho_{0}$

$\eta / \eta_{0}$

Calculated partial specific volume

Primary component

Secondary component
$0.87 \mathrm{~g} . \mathrm{NaCl} / 100 \mathrm{ml} . \quad 21.98 \mathrm{~g} . \mathrm{NaCl} / 100 \mathrm{ml}$.

$\begin{array}{ll}566 \cdot 7 & 84 \cdot 6 \\ 295 \cdot 3 & 38 \cdot 0 \\ & \\ 1 \cdot 0044 & 1 \cdot 142 \\ 1 \cdot 014 & 1 \cdot 51\end{array}$

$0 \cdot 847$

$0 \cdot 851$

axial ratios derived by electron microscopy in a calculation of particle dimensions from sedimentation data is justified since these ratios are independent of absolute dimensions and therefore require no knowledge of magnification factors. Thus particle dimensions obtained by the present calculations may be compared with those obtained entirely by electron microscopy, in order to assess the validity of the procedures employed.

Table 8. Estimation from sedimentation data of particle dimensions of components of the infective fraction

\begin{tabular}{|c|c|c|c|c|}
\hline \multirow{2}{*}{ Identification } & \multicolumn{2}{|c|}{ First } & \multicolumn{2}{|c|}{ Second } \\
\hline & & & & \\
\hline Component & $625 S$ & $330 S$ & $625 S$ & $330 S$ \\
\hline Shape of particle & Rod & Sphere & Sphere & Rod \\
\hline Axial ratio & $2 \cdot 55$ & $1 \cdot 00$ & $1 \cdot 00$ & $2 \cdot 55$ \\
\hline Frictional ratio & 1.082 & $1 \cdot 00$ & $1 \cdot 00$ & $1 \cdot 082$ \\
\hline $\begin{array}{l}\text { Diameter of sphere or equivalent } \\
\text { sphere }(\mathrm{m} \mu .)\end{array}$ & 83 & 58 & 79 & 60 \\
\hline Length of $\operatorname{rod}(\mathrm{m} \mu)$. & 155 & - & - & 113 \\
\hline Diameter of $\operatorname{rod}(\mathrm{m} \mu)$. & 61 & - & - & 44 \\
\hline
\end{tabular}

Table 8 summarizes the data required for the calculation, and the particle dimensions derived. The calculation adopts a partial specific volume of $\mathbf{0 . 8 5 0}$ for both components and treats the rod as a prolate spheroid. Table 8 presents the two possible identifications : the first regards the primary $625 S$ component as the rod and the secondary $330 S$ component as the sphere; the second identification reverses this. The particle dimensions obtained on the basis of the first identification are consistent with those obtained by electron microscopy, and it is reasonable therefore to interpret the primary $625 \mathrm{~S}$ component as a rod of length $155 \mathrm{~m} \mu$., and diameter $61 \mathrm{~m} \mu$. The secondary $330 S$ component is interpreted as an almost spherical granule of diameter $58 \mathrm{~m} \mu$.

Ultrafiltration studies by Galloway \& Elford (1933) indicated a particle size 
of 70-100 $\mathrm{m} \mu$. for the infective component in guinea-pig vesicular fluid. Later ultracentrifugation studies by Elford \& Galloway (1937) by the invertedcapillary tube technique indicated a particle diameter of $74 \mathrm{~m} \mu$. on the assumption of a particle density of $\mathbf{1 \cdot 2 0}$. These particle diameters are in excellent agreement with the diameters of the equivalent spheres, $79-83 \mathrm{~m} \mu$., obtained in the present study for the $625 S$ infective component in infective egg fluids (cf. Table 8).

Electron microscopy of concentrates of the infective component. During this work twelve separate concentrates of the infective component (cf. Table 4) were studied in the electron microscope. Micrographs were obtained within 2 or 3 days of the final concentration procedure, and in most cases at least two fields containing from thirty to sixty discrete particles were measured in detail in each case. Typical data for the dimensions obtained are given in Table 9; typical particle-size distributions are shown in Fig. 7, and typical

Table 9. Typical data for the dimensions of characteristic particles in electron micrographs of concentrates of the infective component

The figures in brackets show the number of discrete particles measured.

\begin{tabular}{|c|c|c|c|c|c|c|}
\hline \multirow[b]{2}{*}{$\begin{array}{c}\text { Source of infective } \\
\text { material }\end{array}$} & \multirow[b]{2}{*}{$\begin{array}{l}\text { Virus } \\
\text { strain }\end{array}$} & \multirow[b]{2}{*}{$\begin{array}{l}\text { Shadowing } \\
\text { metal }\end{array}$} & \multicolumn{3}{|c|}{ Rod } & \multirow{2}{*}{$\begin{array}{l}\text { Spherical } \\
\text { granule } \\
\text { diameter } \\
(\mathrm{m} \mu .)\end{array}$} \\
\hline & & & $\begin{array}{l}\text { Length } \\
(\mathrm{m} \mu .)\end{array}$ & $\begin{array}{l}\text { Diameter } \\
(\mathbf{m} \mu .)\end{array}$ & $\begin{array}{l}\text { Axial } \\
\text { ratio }\end{array}$ & \\
\hline $\begin{array}{l}\text { Saline suspension } \\
\text { of allantoic mem- } \\
\text { branes }\end{array}$ & NJ.M & Gold-manganin & $175 \pm 25(10)$ & $66 \pm 7$ & $2 \cdot 65$ & $67 \pm 9(15)$ \\
\hline $\begin{array}{l}\text { Bovine tongue } \\
\text { epithelium, 6th } \\
\text { bovine passage }\end{array}$ & Ind.C. & Gold-manganin & $193 \pm 19(5)$ & $77 \pm 8$ & $2 \cdot 50$ & $71 \pm 7(175)$ \\
\hline Allantoic fluid & NJ.M & Gold-manganin & $173 \pm 16(27)$ & $67 \pm 10$ & $2 \cdot 57$ & . \\
\hline Pooled egg fluids & Ind.C & Gold-manganin & $180 \pm 16(39)$ & $71 \pm 3$ & $\mathbf{2 . 5 5}$ & . \\
\hline Pooled egg fluids & Ind.C & Gold-manganin & $170 \pm 19(55)$ & $61 \pm 12$ & $\mathbf{2} \cdot 80$ & . \\
\hline Pooled egg fluids & Ind.C & Gold-manganin & $176 \pm 23(56)$ & $71 \pm 10$ & $2 \cdot 46$ & $59 \pm 13(182)$ \\
\hline Pooled egg fluids & Ind.C & Chromium & $164 \pm 29(50)$ & $70 \pm 15$ & $2 \cdot 32$ & $69 \pm 16(261)$ \\
\hline Pooled egg fluids & Ind.C & None & $138 \pm 26(50)$ & $59 \pm 17$ & $\mathbf{2 \cdot 3 4}$ & $54 \pm 9(447)$ \\
\hline Overall means & • & & $175 \mathrm{~m} \mu$. & $69 \mathrm{~m} \mu$. & $\mathbf{2 \cdot 5 5}$ & $65 \mathrm{~m} \mu$. \\
\hline
\end{tabular}

micrographs in Pl. 2. The rod, of mean axial ratio $\mathbf{2 \cdot 5 5}$, was regularly observed and is regarded as the characteristic particle to be associated with the major infective component. The rod was absent from micrographs of control concentrates of normal pooled egg fluids and from micrographs of concentrates of the complement-fixing fraction.

In some micrographs the rods were accompanied by almost spherical granules of about the same diameter but of much greater contrast. The observation of this characteristic granule in electron micrographs of otherwise typical concentrates of the infective fraction suggests that it may arise from the breakdown of the primary rod. This view is consistent with the correspondence between the diameters of the rods and granules and with the existence of terminal granules of relatively greater contrast in the images of many rods (cf. Pl. 2). The observation of the secondary sedimentation boundary in the 
optical-ultracentrifugal analyses of these infective concentrates supports the same conclusion.

The average dimensions of the $\operatorname{rod}, 175 \times 69 \mathrm{~m} \mu$., and of the granule, $65 \mathrm{~m} \mu$, obtained from electron micrographs compare very favourably with the dimensions based on sedimentation data (cf. Table 8) of $155 \times 61 \mathrm{~m} \mu$. for the rod and $58 \mathrm{~m} \mu$. for the granule. Differences between the dimensions obtained by the two methods are not significant in view of the standard deviations quoted in Table 9. Drying and shadowing artefacts in electron microscopy, and assumptions with regard to shape, hydration and density in sedimentation analyses, must all contribute to the variations and differences observed. Final estimates based on both methods for the average dimensions of the characteristic particles in concentrates of the infective fraction are: length of rod, $165 \mathrm{~m} \mu$.; diameter of rod, $65 \mathrm{~m} \mu$.; diameter of granule, $62 \mathrm{~m} \mu$. These mean values are probably correct to within $\pm 10 \%$.

Micrographs of concentrates of the infective fraction frequently showed rods in which about four transverse striations or turns of a spiral were identified. In addition, many rods exhibited at one end single trailing filaments of about $15 \mathrm{~m} \mu$. diameter. Isolated filaments, frequently beaded, were also present. Granules and fragments of rods were observed in pairs lying side by side. Examples of such structures are circled in the micrographs of Pl. 2. These features are consistent with an interpretation of the structure of the intact rod as a coiled spring or platelet stack, capped by a single terminal granule. The evident fragility of the characteristic rod with respect to the methods of specimen preparation may account for the observed spreads of lengths and axial ratios (cf. Fig. 7). The possibility, however, that the data presented for the dimensions of the characteristic rod relate only to the most frequent fragment and that the intact rod is of greater length and rarely encountered under the present conditions, seems unlikely in view of the close correspondence between the data obtained by sedimentation analysis and from electron micrographs.

Micrographs of supernatant fractions associated with complement-fixing activity showed no characteristic features which could be distinguished with certainty from the non-specific content of the specimens. Many spherical particles of diameter $10-15 \mathrm{~m} \mu$. were observed but these, although not inconsistent with the $20 S$ component identified by sedimentation analysis, have not been related specifically to complement-fixing activity.

During the preparation of this paper, Chow, Chow \& Hanson (1954) published an account of the morphology of vesicular stomatitis virus as revealed by the electron microscope. These authors, using an egg-passaged virus of the New Jersey strain, found rod-shaped particles of average length $210 \mathrm{~m} \mu$. and diameter $60 \mathrm{~m} \mu$. They also reported that " the hair-like projections barely visible at the terminal ends and the slight subterminal enlargement may be the result of dehydration during preparation'. These findings are not inconsistent with the data presented in this section.

The minor infective component. It has thus been shown that the major part of the infectivity of suspensions of the virus system of vesicular stomatitis is associated with a rapidly sedimenting component of sedimentation coefficient 
$625 S$. For many further experiments, particularly following the recognition of the complexity of the relatively slowly sedimenting complement-fixing component, it was required to obtain supernatant fractions of maximum complement-fixing activity yet minimum infectivity. To provide such fractions clarified starting materials were ultracentrifuged in the inclined tubes of the $C$ rotor at $G$ values of from 2 to 4 units. The resulting standard supernatant
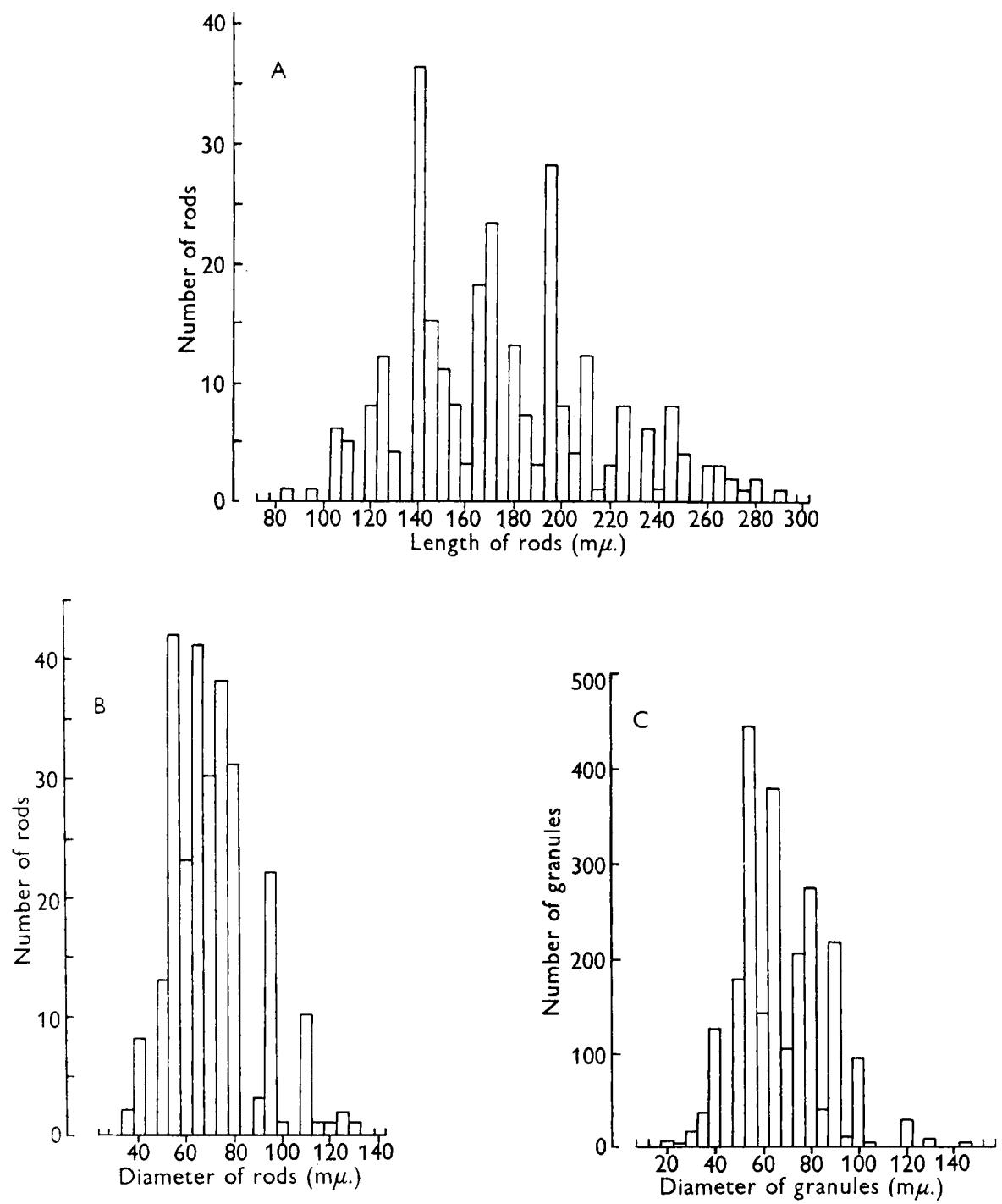

Fig. 7. A : distribution of lengths for 270 rods in micrographs of concentrates of the infective fraction. Average length of rods, $176 \mathrm{~m} \mu$. These data relate to five consecutive experiments which include the last three experiments of Table 9. B : distribution of diameters for 270 rods in $\mathrm{A}$; average diameter of rods, $71 \mathrm{~m} \mu$. C: distribution of diameters for 2300 granules in micrographs of concentrates of the infective fraction; average diameter of granules, $68 \mathrm{~m} \mu$. 
fluids were carried forward immediately for second cycles of ultracentrifugation at the same $G$ values, and so on up to the 3rd or 4th cycle of ultracentrifugation. Alternatively, the $G$ values were increased geometrically at each cycle up to 30 or 40 units of $G$ at the 4 th cycle. The starting materials and successive standard supernatant fluids were titrated for infectivity and complementfixing activity. Typical results for egg and guinea-pig materials are shown in Fig. 8. It is apparent that although the infectivity titres fell rapidly by 2 or 3

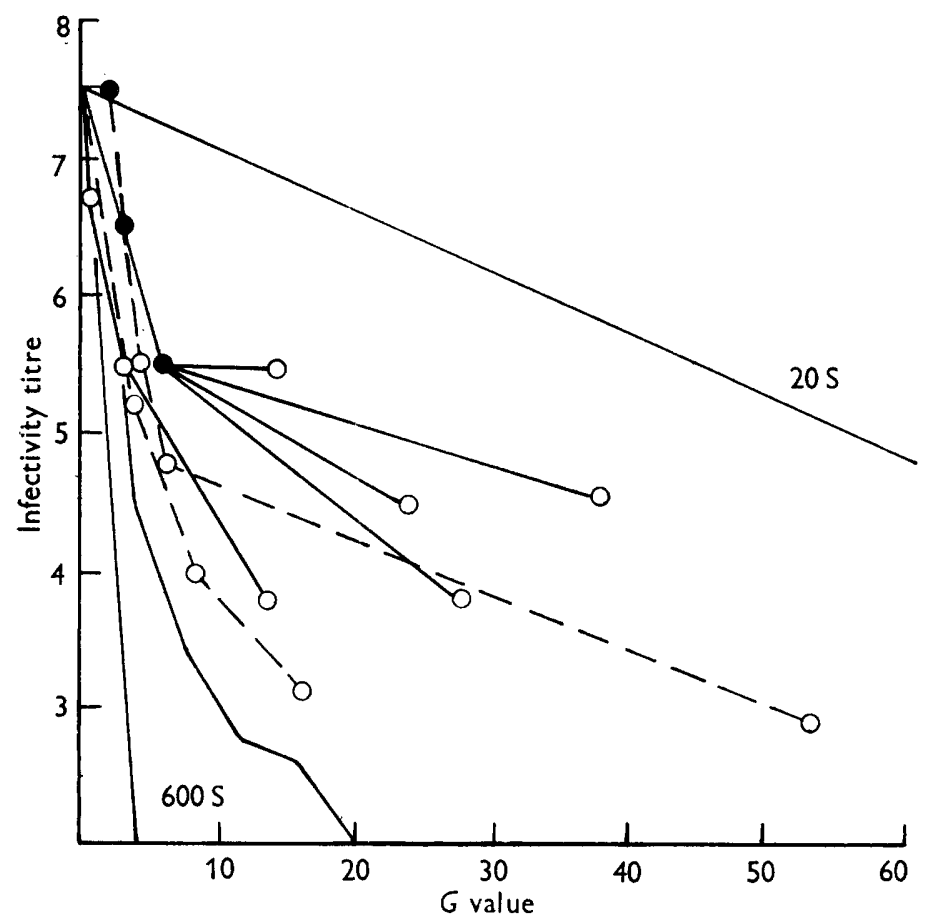

Fig. 8. Decreases in infectivity of standard supernatant samples derived from clarified starting materials following several cycles of ultracentrifugation. $O=$ inclined tubes of $D$ rotor, $12.5 \mathrm{ml}$. withdrawn from $25 \mathrm{ml}$. loaded. $\bigcirc=$ inclined tubes of $C$ rotor, $5 \mathrm{ml}$. withdrawn from $8 \mathrm{ml}$. loaded. An ultracentrifugation of, say, three cycles at 4 units of $G$ is indicated by points at $0,4,8,12$ on the horizontal scale of $G$. The straight lines indicate the behaviour of ideal monodisperse components of sedimentation coefficients $600 \mathrm{~S}$ and $20 \mathrm{~S}$. $=$ suspension of guinea-pig pad epithelium, 15th passage of virus of strain Ind.C. See Table 5 for additional data. All other starting materials were pooled egg fluids infected with virus of strain Ind.C.

logarithmic units in the early cycles the remaining infectivity was removed much less readily. Thus, even after 3 or 4 cycles of ultracentrifugation under conditions appropriate to the deposition of the major infective component, the supernatant samples retained up to 1 part in 1000 of the initial infectivity. The rates of decrease of infectivity during the later cycles of ultracentrifugation (cf. Fig. 8) and the association of the residual infectivity with the complementfixing component already characterized, suggested the presence of the minor infective component of sedimentation coefficient about $20 S$. 
In additional experiments with radial tubes in the swinging-cup rotor, the third-or fourth-cycle supernatant fractions obtained above were loaded into the duralumin cups with anti-convection grids $(k=420)$ or, for the third experiment, into the $0.5 \mathrm{ml}$. plastic inserts $(k=335)$. In four separate experiments at 17, 20, 20, 14 units of $G$, respectively, the infectivity titres of the standard supernatant samples were $0 \cdot 7,1 \cdot 7,0 \cdot 7,0 \cdot 7$ logarithmic units lower than those of the fractions loaded. The starting material for the first experiment was a suspension of guinea-pig pad epithelium obtained at the 15th passage in guinea-pigs of virus of strain Ind.C. These data imply a minimum sedimentation coefficient of about $20 S$ for the minor infective component.

The results of these preliminary experiments are consistent with the existence in the virus system of vesicular stomatitis of a minor infective component, of sedimentation coefficient about $20 S$, which contributes up to 1 part in 1000 of the initial infectivity of the starting material. This component may be associated with complement-fixing activity and may be identical with the $20 S$ complement-fixing component.

The influence of a number of factors upon the assay and stability of infectivity and complement-fixing activity

Exposure to light. The influence of exposure to light upon the infectivity of the unfractionated virus system was reported by Skinner \& Bradish (1954). In additional experiments second-cycle concentrates of the major infective component (cf. Table 4) were exposed in McCartney bottles at $4^{\circ}$ to a daylight intensity of about $250 \mathrm{ft}$.c. In one experiment samples of a dilution of a typical concentrate were exposed to daylight for $\mathbf{0 . 7 5}$ and for $5 \mathrm{hr}$. A third sample was stored in the dark at $4^{\circ}$ for $5 \mathrm{hr}$. The observed infectivity titres were $3 \cdot 5,2 \cdot 0$ and $7 \cdot 2$, respectively. In a second experiment one sample was exposed to light for $1 \mathrm{hr}$. while the second was stored in the dark at $4^{\circ}$ for $1 \mathrm{hr}$. The observed infectivity titres were $5 \cdot 7$ and $7 \cdot 4$, respectively. The minimum rate of decrease of infectivity observed in these experiments, $1 \cdot 7$ logarithmic units $/ \mathrm{hr}$., emphasizes the importance of the precautions adopted in this work to minimize exposure to light.

Complement-fixing activity is considerably less sensitive than infectivity to inactivation by exposure to light. Two unfractionated starting materials and two second-cycle supernatant fractions of the complement-fixing component were exposed at $4^{\circ}$ to an artificial light intensity of $3000 \mathrm{ft}$.c. for $1-3 \mathrm{hr}$. A decrease of complement-fixing activity of only $20 \pm 7 \%$ was observed in these four experiments. Thus exposure to light under normal experimental conditions was without significant influence on the complement-fixing activity of the fractions studied.

Storage in the dark. Clarified starting materials, second-cycle upper supernatant fractions of the complement-fixing component, and second-cycle concentrates of the infective component were stored in the dark for 1 and $24 \mathrm{hr}$. at 4,20 and $37^{\circ}$. In no case did the observed change in the degree of complement-fixing activity exceed the $\pm 15 \%$ accuracy of the test. Thus the 
complement-fixing activity of the fractions studied was not modified significantly by storage for short periods at temperatures up to $37^{\circ}$.

Exposure to $56^{\circ}$ for $1 \mathrm{hr}$. The exposure of the samples listed in the previous paragraph to $56^{\circ}$ for $1 \mathrm{hr}$. regularly decreased the complement-fixing activity to $10 \%$ or less of the initial level. The corresponding components in the virus system of foot-and-mouth disease, when treated in this manner, retained at least $70 \%$ of their initial complement-fixing activity, indicating a significantly greater resistance to inactivation by heating.

Titration of infectivity in eggs and guinea-pigs. During the course of this work four clarified starting materials, two third-cycle concentrates of the infective component and two upper supernatant fractions of the complementfixing component were titrated in parallel in eggs (9 per dilution) and guineapigs (10 per dilution). In these groups the 'egg' titres exceeded the 'guinea-pig' titres by $3 \cdot 7 \pm 0 \cdot 2,4 \cdot 0 \pm 1 \cdot 0$ and $3 \cdot 6 \pm 0 \cdot 3$ logarithmic units, respectively. These data indicate a constant difference of about four logarithmic units between the infectivity titres indicated by the two hosts. The nature of the fraction inoculated was without apparent influence. Thus, on a relative scale of infectivity, these hosts would provide identical results in any study of the present kind.

\section{DISCUSSION}

The data presented in this paper demonstrate the complexity of the virus system of vesicular stomatitis as observed in infective egg fluids. The four components identified, of sedimentation coefficients $625 S, 330 S, c .20 S$ and $c .6 S$, may originate in two ways. It may be considered either that these components are distinct and separate products of the process of virus multiplication or that they arise from the disintegration of a single infective component. These interpretations are not mutually exclusive and either could result in similar biophysical findings. The data presented support the view that the components identified are representative of those which exist in egg fluids infected with virus of strain Ind.C.

The $625 S$ component, identified as the major infective component, exists as a rod of dimensions $165 \times 65 \mathrm{~m} \mu$. and is associated with about $35 \%$ of the initial complement-fixing activity. The $20 S$ component is probably also infective but does not contribute more than about $0 \cdot 1 \%$ of the initial infectivity. The $330 \mathrm{~S}$ component, a compact spherical granule of diameter $62 \mathrm{~m} \mu$., probably arises from the disintegration of the rod and may not be infective. The few experiments made with egg fluids infected with virus of strain NJ.M and with guinea-pig- or bovine-passaged virus of strain Ind.C confirm these findings and do not reveal any host- or strain-variations.

The structure of the infective rod suggested by the electron micrographs, a coiled beaded filament or a platelet stack capped by an almost spherical granule of about the same diameter, is consistent with the observed sedimentation properties. Thus the $20 S$ and $6 S$ complement-fixing components may be fragments produced by the disruption of this filament. The implications of these components and possible structures in relation to chemical composition and 
the mechanism of virus multiplication and decay cannot be discussed further until the kinetics of the interaction between the host cell and the complex virus system have been more fully investigated.

The multiplicity of components in the virus system of vesicular stomatitis as observed in infective egg fluids, together with the complexity of structure indicated by electron microscopy, demand further study of the relationship between physico-chemical structure and biological function. Of particular interest is the problem of the significance in the infective process of the smaller components in the virus system of vesicular stomatitis and foot-and-mouth disease, and possibly also of other virus diseases. By present techniques the study of components which may contribute only a small part of the total infectivity of a virus system is complicated by the contamination of fractions by residues of the major infective components. Despite these limitations, the association of trace infectivity with the $20 S$ component in the virus system of vesicular stomatitis is indicated strongly by the present observations.

In this paper the complement-fixing fraction has not been referred to as the 'soluble antigen' but has been defined directly in terms of its sedimentation properties as the $20 S$ and $6 S$ components. These sedimentation coefficients correspond with equivalent particle diameters of about 11 and $6 \mathrm{~m} \mu$., respectively. Both the present study and an earlier study of the virus system of foot-and-mouth disease (Bradish et al. 1952) indicate the presence of components which are significantly smaller than the basic subunit of about $12 \mathrm{~m} \mu$. diameter required by Polsen's postulate (1953).

It is a pleasure to thank Miss N. Smart and Dr R. C. Backus for their collaboration during part of this work. The valuable criticism and advice given by Dr I. A. Galloway, the Director of this Institute, is acknowledged with gratitude. Our grateful thanks are also given to Mr E. Scoates, for undertaking many of the complementfixation tests, and to Misses H. Wigman and C. Worner and Messrs T. Burrows, J. German, J. Kirkham, P. Mitchell and A. Wells for other competent assistance.

\section{REFERENCES}

Backus, R. C. \& Williams, R. C. (1948). Some uses of uniform sized spherical particles. J. appl. Phys. 19, 1186.

Beveridge, W. I. B. \& Burnet, F. M. (1946). The cultivation of viruses and rickettsiae in the chick embryo. Spec. Rep. Ser. med. Res. Coun., Lond., no. 256.

Bradish, C. J., Brooksby, J. B., Dillon, Jun., J. F. \& Norambuena, M. (1952). Ultracentrifugal studies of the infective and complement-fixing components in the virus system of foot-and-mouth disease. Proc. roy. Soc. B, 140, 107.

Brooksвy, J. B. (1952). The technique of complement fixation in foot-and-mouth disease research. Spec. Rep. Ser. agric. Res. Coun., Lond., no. 12.

Chow, T. L., Chow, F. H. \& Hanson, R. P. (1954). Morphology of vesicular stomatitis virus. J. Bact. 68, 724.

Elford, W. J. \& Galloway, I. A. (1937). Centrifugation studies. III. The viruses of foot-and-mouth disease and vesicular stomatitis. Brit. J. exp. Path. 18, 155.

Galloway, I. A. \& Elford, W. J. (1933). The differentiation of the virus of vesicular stomatitis from the virus of foot-and-mouth disease by filtration. Brit. J. exp. Path. 14, 400. 
Hillier, J. \& Ramberg, E. G. (1947). Magnetic electron microscope objective: contour phenomena and the attainment of high resolving power. J. appl. Phys. $18,48$.

Ma, T. S. \& ZuazaGa, G. (1942). Micro-Kjeldahl determination of nitrogen. Industr. Engng Chem. (Anal. ed.), 14, 280.

Markham, R. (1942). A steam distillation micro-Kjeldahl apparatus. Biochem. $J$. 36, 790 .

Polsen, A. (1953). Weight relationships among animal viruses. Nature, Lond., 174, 1154.

RANDRUP, A. (1954). Ultracentrifugation of the virus of foot-and-mouth disease. III. Verification of the existence of two particles of different size carrying the complement-fixing antigen. Acta path. microbiol. scand. 34, 355.

Reed, L. T. \& Muench, H. (1938). A simple method of estimating 50 per cent endpoints. Amer. J. Hyg. 27, 493.

Scotr, G. D. (1949). Spherical particles for electron microscopy. J. appl. Phys. 20, 417.

Skinner, H. H. \& Bradish, C. J. (1954). Exposure to light as a source of error in the estimation of the infectivity of virus suspensions. J. gen. Microbiol. 10, 377.

Svedberg, T. \& Pedersen, K. O. (1940). The ultracentrifuge. Oxford: Clarendon Press.

\section{EXPLANATION OF PLATES}

\section{Plate 1}

Fig. 1. Sedimentation diagrams for components of concentrate of complement-fixing fraction. Nitrogen content of concentrate, $0.06 \mathrm{mg} . \mathrm{N} / \mathrm{ml}$; cell length $=30 \mathrm{~mm}$., $\theta=35^{\circ}$. Exposures taken 20, 30, 40 min. after attainment of 40,000 rev./min. Corrected sedimentation coefficients $20 \cdot 0 S$ and $7 \cdot 3 S$.

Fig. 2. Sedimentation diagrams for components of concentrate of infective fraction. Nitrogen content of concentrate, $0 \cdot 10 \mathrm{mg} . \mathrm{N} / \mathrm{ml}$; ; cell length $=30 \mathrm{~mm}$., $\theta=20,15,15,15^{\circ}$. Exposures taken 20,30, 40, $50 \mathrm{~min}$. after attainment of $7000 \mathrm{rev} . / \mathrm{min}$. Corrected sedimentation coefficients $599 S$ and $317 S$.

Plate 2

Electron micrographs of concentrates of the infective fraction derived from pooled egg fluids infected with virus strain Ind.C. Fig. 3 : fivefold dilution of third-cycle resuspended deposit. Fig. 4: undiluted second-cycle resuspended deposit, see fifth entry in Table 9. Fig. 5 : tenfold dilution of third-cycle resuspended deposit as used in Fig. 3. Figs. 3 and 4 show typical rods; Fig. 5 shows granules with some rods. Other features are indicated as follows: $\boldsymbol{R}=$ rods with dense terminal granules; $S=$ rods showing cross bands or striations; $\boldsymbol{F}=$ trailing or isolated filaments; $\boldsymbol{R} \boldsymbol{G}=$ rods or rod fragments associated with detached granules. 
Journal of General Microbiology, Vol. 14, No. 2

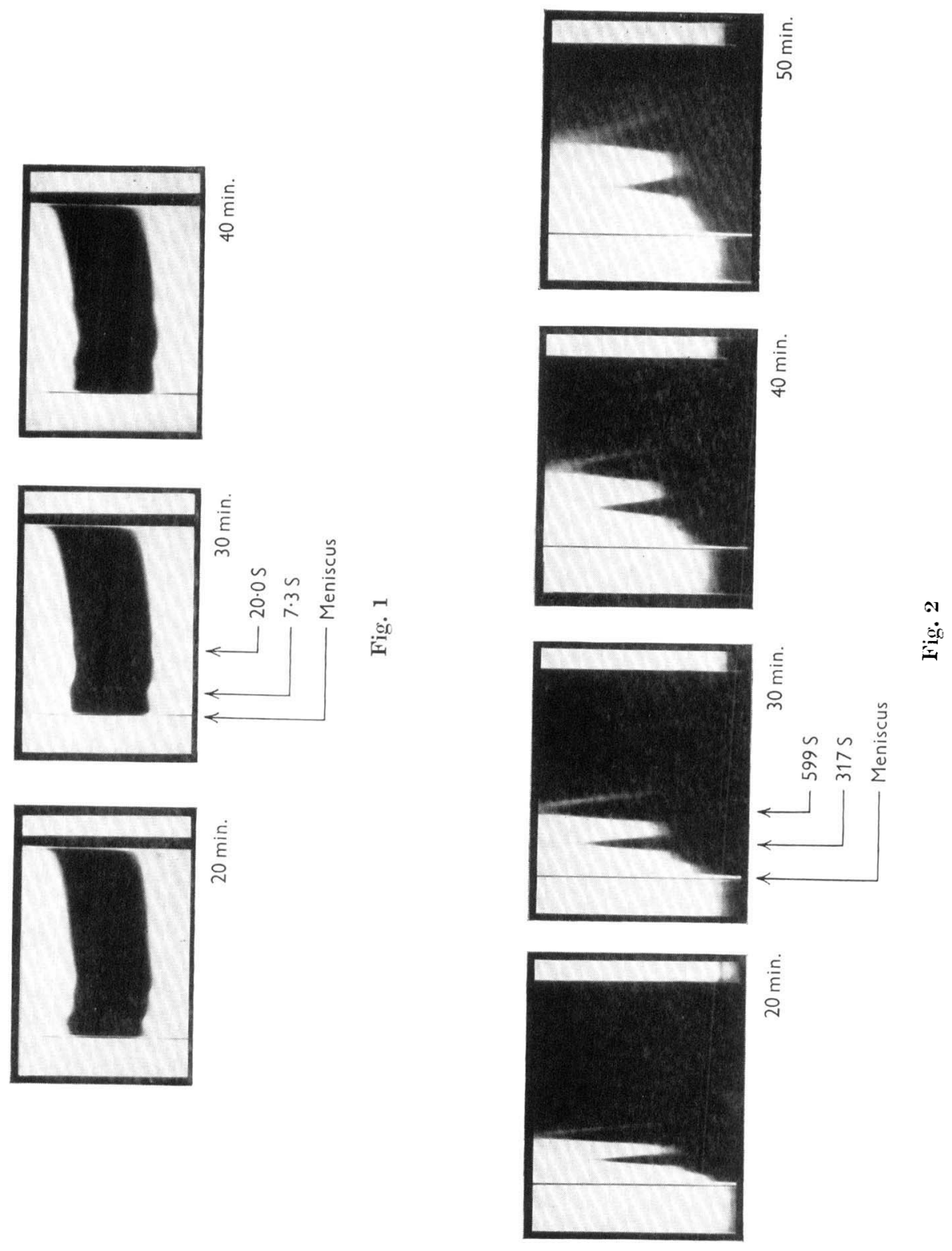

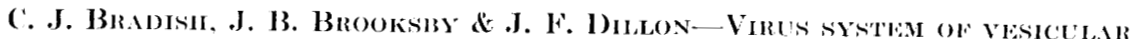
stomatitis. Pratef 1

(Facing p. :314) 
Journal of General Microbiology, Vol. 14, No. 2
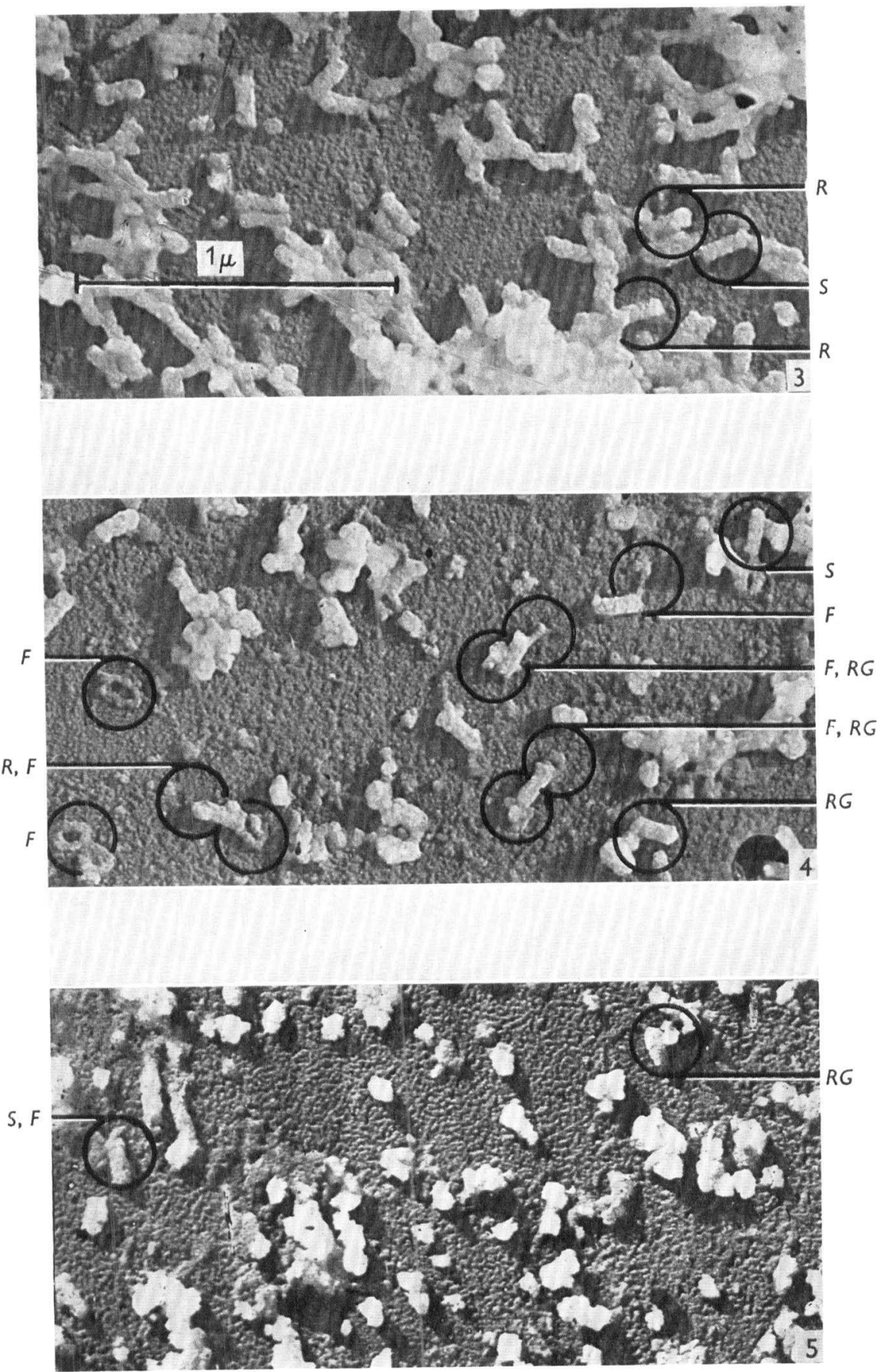

C. J. Brapisi, J. B. Brooksby \& J. F. Dillon-Virus system of vesiculak STOMatitis. Plate 2 